Original Research

\title{
Acute Care Decision-Making for Patients with Advanced Dementia: An Exploratory Study Using Cognitive Task Analysis
}

Meira Erel ${ }^{1,+, *}$, Esther-Lee Marcus ${ }^{1,2,{ }^{+}}$, Freda DeKeyser Ganz ${ }^{1,3}$

1. Henrietta Szold Hadassah University School of Nursing, Kiryat Hadassah, POB 12000, Jerusalem, 91120, Israel; E-Mails: meiraerel@walla.co.il; estherlee@herzoghospital.org; elm@zahav.net.il; Freda@jct.ac.il

2. Faculty of Medicine, Hebrew University of Jerusalem, Israel; Department of Geriatrics, HerzogMedical Center, Jerusalem 91035, Israel

3. Jerusalem College of Technology, 11 Beit Hadfus, Jerusalem 9548311, Israel

† These authors contributed equally to this work.

* Correspondence: Meira Erel; E-Mail: meira@walla.co.il

Academic Editor: Ladislav Volicer

Special Issue: Advanced Dementia: Enjoy It or Avoid It?

\section{OBM Geriatrics}

2021, volume 5, issue 1

doi:10.21926/obm.geriatr.2101159
Received: November 11, 2020

Accepted: February 20, 2021

Published: March 01, 2021

\begin{abstract}
Decision-making by medical and health care staff forms the core of professional practice. Thought processes, including non-clinical considerations, significantly impact how clinical decisions are made. Such considerations become more relevant when addressing end-of-life care decisions for patients with advanced dementia (PAD). Though palliative care is recommended for this population, its implementation tends to vary. Given the medical staff's significant influence in guiding clinical decisions, we examined thought processes that accompany staff decisions. We used Cognitive Task Analysis (CTA) to analyze interviews conducted with 15 physicians and 11 nurses working in acute care wards in Central Israel. Participants were interviewed regarding their clinical decision-making in a hypothetical scenario of a PAD who presents with an acute, potentially life-threatening medical problem.
\end{abstract}

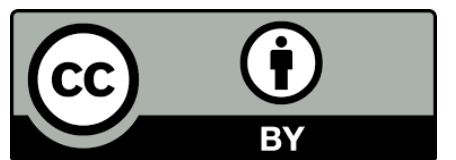

(C) 2021 by the author. This is an open access article distributed under the conditions of the Creative Commons by Attribution License, which permits unrestricted use, distribution, and reproduction in any medium or format, provided the original work is correctly cited. 
Moral judgment orientation was the primary factor affecting clinical decision-making for advanced dementia, with a pronounced dichotomous split between deontological and utilitarian approaches. This polarization was highly associated with the medical specialty. Practitioners in surgical wards tended to focus on the patient's current medical condition, as an isolated or disease-centered illness perspective, supported by deontological moral lines of thinking. This perspective was contrary to that of staff in medical wards who mostly treated the patient from a holistic perspective with a patient-focus approach, supported by utilitarian moral lines of thinking. Although all respondents presented the patient or family as primary decision partners, the practitioners were motivated to make decisions based on unit hierarchies or positions of authority figures. Therefore, clinical end-of-life decisions are influenced by different thinking processes of the health staff and several non-clinical factors. The moral thinking paradigm was found to be associated with a professional orientation. Understanding the subjective, non-clinical aspects of decision-making for PAD might improve end-of-life care in this population.

\section{Keywords}

Advanced dementia; cognitive task analysis; decision-making; end-of-life care; moral thinking; palliative care; thought process; qualitative study

\section{Introduction}

Technological advances in medicine have highlighted the need for thoughtful decision-making regarding the continuance of aggressive care or changing the goals of palliative and end-of-life care. Advanced dementia is a common etiology where such decisions are crucial [1]. Aggressive care is not always desirable for this patient population and might be considered futile care. In addition, aggressive care may cause more burden than a benefit and does not conform to the guidelines and recommendations for patients with advanced dementia (PAD) promoted by major international geriatric organizations [2-4]. While uniform recommendations exist for palliative care for this patient population, there is considerable variation in their implementation. This variability is common in non-geriatric in-patient departments such as medical or general surgery wards as well as in outpatient departments [5, 6].

Despite the availability of vast literature concerning the end-of-life treatment decisions for patients with advanced dementia, few studies have evaluated the thought processes behind decisions made by healthcare personnel. A medical team acts as the primary driver in clinical decision-making and selecting the suitable treatment approach [7]. Healthcare staff leads the care management, is the primary source of medical knowledge, and a change agent in the patient's care. In addition, non-clinical factors can affect the clinical decision-making processes [8].

Clinical decisions are made based on the judgment of the medical condition of the patient $[9,10]$. In the case of advanced dementia, clinical decisions include end-of-life issues that intrinsically involve moral implications [11]. Moral judgment is based on two mental processes: deontological and utilitarian thinking. Deontological thinking includes intuitive, emotional processes and focuses 
on prompt action and immediate aspects of the situation. Utilitarian judgment is based on conscious-controlled reasoning that focuses on outcomes of the considered acts [10-13].

The primary objective of the current study was to examine the thinking processes of medical personnel when making end-of-life treatment decisions for PAD. The secondary objective was to describe the barriers associated with the implementation of palliative care for PAD. We describe the results of a qualitative study based on 26 interviews conducted with nurses and physicians working in acute care in-patient wards in Israel.

\section{Materials and Methods}

\subsection{Study Design}

This was a phenomenological qualitative, interview-based descriptive study [14]. The study was approved by the research ethics committees (case number 5535-18-SMC; 0027-19-HMO) of two hospitals.

\subsection{Samples}

Participants included 15 physicians and 11 nurses working in acute in-patient general medical and surgical wards at two hospitals in central Israel. Inclusion criteria were physicians and nurses with no formal geriatric or palliative care training. A convenience sample was recruited during staff meetings of both physicians and nurses. Recruitment of participants continued until thematic saturation was obtained.

\subsection{Data Collection}

Physicians and nurses who were interested in participating in the study contacted one of the researchers (M.E.) to fix an appointment for the interview. Informed consent was obtained, and interviews were conducted in the hospitals. Participants were provided code numbers to protect their anonymity. Numerical coding of the interviews was according to the profession (physician, nurse), type of ward (medical ward, surgical ward), and seniority (senior, junior staff), resulting in six groups of participants. Interviews were numbered sequentially within each group. Data of the recorded and transcribed interviews were kept in a secure desktop with secured password accessibility only to the first author of this study (M.E), where the data were anonymized. The interviews were conducted in the Hebrew language.

A hypothetical medical scenario (Table 1 ) was presented describing an acute medical condition where the PAD was terminally ill. Interviews commenced with an open, neutral question aimed at discovering the participants' perception of the scenario. Participants were asked to select an appropriate treatment for the patient. Treatments ranged from immediate and life-saving procedures such as surgery or invasive interventions (the "aggressive" approach) to treatment based on alleviating suffering and focusing on improving the quality of life, with no treatments or interventions directed toward extending the life (the "palliative approach"). Further questions included a detailed description of task priorities and meanings and perceptions of the scenario (Table 1). All interviews were audio-recorded and transcribed verbatim. 
Table 1 Case scenario and interview guide questions.

Case Scenario
You are in charge of treating an 80 -year-old male who was diagnosed with Alzheimer's disease
five years ago. The patient lives at his home with a personal caregiver. Currently, he does not
recognize family members, does not communicate verbally, and needs total assistance with
mobility and basic functioning, and suffers from urinary and bowel incontinence. The patient was
admitted to your hospital for extreme restlessness and abdominal bloating. According to his
caregiver, he has been constipated for four days and refuses to eat. A physical examination
revealed an absence of bowel sounds. Abdominal imaging showed dilated intestinal loops and a
space-occupying lesion, a finding suggestive of colon cancer.

\section{Questions}

1. Describe in four- to seven general steps your actions and response to the case presented.

2. Were there any "hints" that helped or directed your care recommendations?

3. Which of the steps constituted the most significant difficulty for you?

4. What caused the difficulty?

5. What feelings, sensations, and thoughts came to your mind?

6. What actions were considered, were available, and/or relevant to you?

7. What criteria did you use to accept or reject these actions?

8. Was there a specific guideline for selecting or rejecting an action?

9. Have you considered any potential issues that may arise from your actions?

10. What were the goals you faced at this time?

11. What did you mainly need to achieve the goals at this point?

12. What information helped you decide whether to implement a specific action?

13. How did you access the necessary information?

14. What did you do with the information?

15. Did the information help you?

16. Were you looking for professional/organizational guidelines that matched the situation?

17. How did you know whether the guidelines were appropriate for the situation?

18. Did you compare the case to a similar situation from your previous experience?

19. Did previous experience guide you in making your decision?

20. Did you consider the potential consequences of your actions?

21. Did you consider possible outcomes?

22. What information helped you to know that this is the right thing to do?

23. What kind of pressure was involved in making treatment decisions?

24. Assuming you had to describe the situation to another person, how would you summarize the case?

\subsection{Data Analysis}

Interviews were analyzed using the Cognitive Task Analysis (CTA) method [15]. CTA is designed to examine mental processes used during decision-making when performing a complex task. The thought processes are categorized into cues, goals and priorities, information seeking, overt and covert thinking patterns, and previous experience (Table 2). 
Table 2 Cognitive Task Analysis Interview Probes Questions.

\begin{tabular}{ll}
\hline Task Diagram & What were the courses of action considered or available to you? \\
\hline Options & Why was this option selected and others were options rejected? \\
& Was there a rule that you were following in selecting this option? \\
& Were there any clues in the case study that directed your attitude? \\
$\begin{array}{l}\text { Cues } \\
\text { Pressure }\end{array}$ & What kind of pressure was involved in making treatment decisions? \\
Goals and priorities & What were your specific goals and objectives at this time? \\
Information seeking & Did you seek any guidelines at this point? \\
& What information did you use? \\
\hline Concept Mapping & \\
\hline $\begin{array}{l}\text { Analogs/Mental models } \\
\text { Experience }\end{array}$ & Did you foresee all the possible consequences of your actions? \\
Situation assessment & Were you reminded of past experiences? \\
\hline
\end{tabular}

Two of the researchers (M.E.; and E-L.M.) independently analyzed the interview responses using these categories and identified themes and subthemes. After discussion, an agreement was reached, and the emerging themes and category analyses were integrated.

We used shape analysis to examine the form of discourse and the use of language, such as repetitive words and pauses during talking [16]. Both longitudinal and lateral approaches of language were used. The longitudinal approach analyzes the use of language during an entire interview of a single informant, and the lateral approach compares the use of language between different informants.

\section{Results}

\subsection{Participants}

There were 26 participants in this study: 15 nurses and 11 physicians. The majority of the respondents $(n=17)$ were from medical wards $(65.4 \%)$, and the remaining $(n=9)$ were from general surgical wards (34.6\%). Interviews lasted for 9 - to $28 \mathrm{~min}$. The sample included both junior $(n=12$, $46.2 \%)$ and senior staff members $(n=14,53.8 \%)$ (Table 3$)$.

Table 3 Participants' Characteristics.

\begin{tabular}{|c|c|c|c|c|}
\hline \multicolumn{2}{|c|}{ Characteristics } & $\begin{array}{l}\text { Medical } \\
\text { Ward } \\
N=17\end{array}$ & $\begin{array}{l}\text { Surgical } \\
\text { Ward } \\
\mathbf{N}=\mathbf{9}\end{array}$ & $\begin{array}{l}\text { Total } \\
\mathbf{N}=26\end{array}$ \\
\hline \multirow{3}{*}{ Role } & lunior-level nurses & 1 & 3 & 7 \\
\hline & Senior-level nurses & 6 & 2 & 8 \\
\hline & $\begin{array}{l}\text { Junior physicians (interns, } \\
\text { residents, and fellows) }\end{array}$ & 4 & 1 & 5 \\
\hline
\end{tabular}




\begin{tabular}{lllll}
\multirow{3}{*}{ Sex } & Attending and senior physicians & 3 & 3 & 6 \\
\multirow{3}{*}{ Age (years) } & Males & 11 & 7 & 18 \\
& Females & 6 & 2 & 8 \\
& $20-30$ & 2 & 2 & 4 \\
& $31-40$ & 7 & 2 & 9 \\
\multirow{3}{*}{ Religion } & $41-50$ & 6 & 2 & 8 \\
& $51-60$ & 2 & 3 & 5 \\
& Jewish & 14 & 7 & 21 \\
\hline
\end{tabular}

\subsection{Major Themes}

Three major themes were found: moral thinking/judgments, family influence, and decision process. The themes were categorized into the following sub-themes, as shown below.

\subsubsection{Theme 1: Moral thinking/judgment}

Some interviewees expressed deontological moral judgments, emphasizing their commitment to address and respond with a focus on an immediate course of treatment.

"There is an immediate medical issue that stands in front of the decision." (an intern junior, surgical ward [01]).

"Medical ethics means to concentrate on the acute/immediate health state." (a junior-level nurse, surgical ward [01]).

"I always tell the family that without an aggressive care/operation, the patient will die. Even if there is a $10 \%$ chance to resolve the acute situation, I need to do everything in my power. I focus on the situation now..., not on the late outcomes." (a senior physician, surgical ward [01]).

Other participants preferred utilitarian moral judgments that emphasized expected outcomes.

"The care decision should concentrate on the poor outcomes expected from acute treatment." (a senior-level nurse, medical ward [05]).

"I start with explaining the care options available, but focus on the expected outcomes. In this case, it is ethically right not to prolong the suffering." (a senior physician, medical ward [02]).

We observed that the type of moral thinking was associated with the medical specialty. There was an almost dichotomous split in the moral thinking between staff from the medical and surgical wards. Subthemes included professional perspectives and goals of care orientation.

Sub-Theme: Professional Perspective. The majority of the staff $(n=13 ; 76.5 \%)$ from the medical wards described a utilitarian approach. The interviewees emphasized that the treatment aimed at preventing the suffering and providing symptom management, without prolonging the life, as the patient is "in poor condition," "not suitable for definitive treatment," "demented, not a candidate for any aggressive treatment," "is not a candidate for surgery, " "a patient with a poor prognosis."

In contrast, nine healthcare professionals from surgical wards selected treatments at the opposite end of the therapeutic spectrum and preferred more invasive care. Most surgeons $(n=7$, $\mathbf{7 7 . 8 \% )}$ focused on the acute situation and prioritized the patient's illness as opposed to a holistic 
approach to the patient. Some respondents commented, "This is an extreme surgical [emergency]," "We have to solve the problem tonight," "We have to do something and to save a life."

While both perspectives focused on alleviating a patient's suffering, the focus of the surgical, deontological perspective was to provide an immediate benefit. Surgeons and surgical ward nursing staff were less likely to perceive or identify the patient's terminal condition. For instance, one physician commented, "if it is just a tumor ... it is not a terminal illness ... ." Two surgeons stated that in the case of a terminally ill patient, palliative care is a legitimate treatment option; however, the hypothetical scenario presented in this study required immediate action. In addition, two surgical physicians stated that the degree of surgical intervention was contingent upon the patient's basic condition and medical history, especially with respect to the extent of existing surgical risk.

Sub-Theme: Goals of Care Orientation. Differences were noticed in the goals of care orientation related to the patient's medical condition and treatment goals. Physicians and nurses in medical wards focused on the quality of life, long-term prognosis, the complexity of the condition, the potential of treatment alternatives, and their significance for the patient's life. Surgeons usually concentrated on the immediate needs of the patient and tended to be task-oriented and techniqueoriented. For example, they stated, "The default is to do, " "It's hard to sit still," "I am used to doing," "I operate on almost everything. "The majority of respondents from both medical and surgical wards focused on one extreme or the other, without expressing a range of treatment options.

"If a patient with dementia suffers now most probably from a tumor, this certainly directs me toward non-aggressive palliative care." (a senior physician, medical ward [02]).

"The patient is going to surgery. There is no room for my moral say or opinion; it is irrelevant. If I know I can save lives by my actions and have the ability to intervene and change this situation, then that's what I do."(a junior surgeon [01]).

"It is rare to give up on a patient, even if they are elderly and demented. As a surgeon, you have a very dramatic intervention during the illness. In surgery, I am used to doing it. I have difficulty not doing it. It is difficult to sit idle and do nothing." (a senior surgeon, surgical ward [03]).

Analysis of the language used by surgeons also indicates their predilection toward activity, initiative, task execution, and invasive procedures. They used phrases such as "fighting, " taking the bull by the horns," "we are very aggressive." No significant differences were observed between physicians and nurses working in both medical and surgical wards regarding goals of care and the tendency to prefer a particular care approach or between physicians and nurses in the surgical wards.

\subsubsection{Theme 2: Family Influence}

Family influence refers to the extent to which family members contribute to or influence care decisions. Family members were consistently considered as major partners in the care decisionmaking.

In most cases, the family has the right to veto decisions made by the healthcare team, even when the family members' decisions are inconsistent with a professional opinion. For example, few respondents said, "I will not go against the family." "[We] all are in concert with the family." or "Even if you think the patient is suffering and that the intervention requested is not in the best interests of the patient, we do everything that the family asks." In two interviews, there was no mention of 
family members as part of the decision-making process. In these cases, the interviewees expressed their tendency toward an "aggressive" treatment approach.

Three physicians did not follow the family's wishes when the opinion of a family member was different from their own. In these extreme cases, the family's autonomy was limited, reflecting the medical paternalistic approach where the physician vetoes medical decisions of the family, in contrast to allowing the family to veto the physicians' decisions.

"I tend toward paternalistic medicine because it seems as if the family does not know what is 'right' for the patient." (a junior physician, medical ward [01]).

"We can't be forced to do anything." (a senior surgeon [03]).

One physician recounted that extreme situations arose where the healthcare staff felt that the family was thrusting their wishes instead of those of the patient, thereby raising ethical issues.

"You can think of all kinds of hidden interests of family members, maybe the patient owns an apartment ... you know ... It's maybe going to a thousand and one directions. If I start to see that there are differences of opinion, I might go in ... maybe even to the institutional legal department for a legal examination, an ethics committee, the management, and so on, to see how to solve it." (a senior surgeon, surgical ward [02]).

"Maybe not asking the family about do not resuscitate (DNR) decisions... but decide as a team consulting...sometimes it is easier not to discuss these matters." (a senior physician, medical ward [03]).

"If we see evidence of an acute situation, like high blood lactate or any life-threatening condition, we do not involve the family, but three doctors sign an official form for acute emergency decisions and proceed to operate in an emergency." (a junior nurse, surgical ward [01]).

\subsubsection{Theme 3: The Decision Process}

Decision-making was influenced by several factors. These factors are communication, hierarchical and legal aspects, and medical authority.

Communication. Several forms of communication were described. Participants indicated their attempts to assess the family members' understanding of the situation and to adjust the discussion accordingly. Of the 26 interviews, 11 (42\%) reported providing information to family members about the patient's terminal condition. Determining the presence of advance directives and end-of-life decisions was reported by $12(46 \%)$ of the respondents. Three interviewees described the difficulty of breaking bad news to the family.

Some participants $(n=6,23 \%)$ reported informing the family of the threatening condition, the futility of aggressive care, stressing the advantages of palliative care.

"I explained to them (family) that aggressive treatment involves a great deal of suffering and considerable mortality." (a senior physician, medical ward [03]).

"I'm talking to them ... there is a very high surgical risk. They [the patients] don't survive the operation at this age... there are no physiological reserves to deal with the condition. Even after a minimal complication such as the pulse rising or electrolyte imbalance...the family should be informed.... ." (a senior surgeon [02]).

In contrast, other interviewers informed the family of the risk of death, in light of the patient's acute condition, to obtain consent to start an aggressive life-saving treatment $(n=5,19 \%)$. 
"I explained the situation to them. I explained that this is a life-threatening condition ... and the immediate treatment is surgery, and said that without this treatment, the patient will probably die." (a senior physician, medical ward [01]).

"I present them the options, including the outcome of each option and about palliative care.... if you decide ... how it is going to end in death." (a junior physician, medical ward [02]).

Hierarchical Aspects. In all interviews with physicians, the department's standard norm of care influenced the treatment approach, and decisions were made only after presenting the case to a senior physician or department head.

Several physicians stated:

"Stems from ... who runs the department."

"In each situation, the team presents the case to a senior physician in charge."

"I pass all the data to the senior for a decision."

However, at the same time, the presentation of the case gets biased in the junior physician's opinion.

A junior physician: "When I speak to him, I already say what I think ... in my opinion so and so ... .$"$

"I'll explain what the consensus is, but the decision will be according to the senior's approach."

About half of the nurses $(n=7)$ did not refer to the decision-making hierarchy within the department, and the interviews reflected the nurse's position on the case presented, based on the nurse's experience, education, and judgment. The other nurses $(n=6)$ reported having a discussion and consultation with the senior physician, and one nurse even added: "Decisions are made according to the department head's approach."

Legal Aspects. Legal aspects were, for the most part, mentioned by physicians, with only one nurse addressing this issue.

"I always think of the legal side. It's not something I take for granted."(a senior surgeon, surgical ward [01]).

Many respondents used legal aspects as a method of taking defensive action to "protect me and defend the system." This approach to document oral communication reflects the level of caution among the physicians discussing end-of-life decisions with the family.

The Use of Medical Authority. Medical authority was described in almost half of the interviews ( $n=12,46 \%)$ as a means to influence or motivate family members to agree to treatments preferred by the medical staff.

"Usually when a person with authority in the department speaks properly, they (family) follow the staff's opinion and their decision." (a senior physician, medical ward [03]).

"I am very emphatic and, at the same time, I use my authority to make my message very clear." (a junior surgeon [01]).

Shape Analysis. In addition to analyzing the content of the interviews, shape analysis was also conducted. The shape analysis examined words that frequently appeared, identified pauses in the discussion, and examined the environment in which the interviews were conducted. We identified two often repeated words in the interviews: "family" and "suffering." "Family" was used especially when discussing the influence of family members on decisions. "Suffer" or "suffering" frequently 
appeared in all interviews, indicating its importance when making treatment decisions. Nurses referred to "suffering" slightly more often $(0.50 \%$ of all counted words) than physicians $(0.39 \%$ of all counted words). In addition, those who preferred a palliative care approach to treatment used the word "suffer" more often ( $0.54 \%$ of all counted words) than those advocating a more aggressive approach to treatment ( $0.30 \%$ of all counted words).

The words, "suffer" or "suffering" were used to justify treatment decisions for both aggressive and palliative care approaches. Interviewees with an aggressive approach highlighted the use of invasive procedures to quickly end the pain and suffering of the patient. In contrast, suffering was used to justify a more conservative approach, avoiding unnecessary treatment for the patient.

Another interesting finding was associated with the discourse sequence. Interviews with some surgeons contained pauses of silence in the conversation when discussing end-of-life issues. We only observed these pauses with participants who did not favor a palliative care approach, and the pauses often preceded comments implying that palliative care was essentially no care at all.

"I witnessed a case where 'the patient was given up' and went for supportive care. I suffered terribly... I felt I was not practicing good medicine. I ran away..... This is the worst...... That you are not willing to do everything possible for the patient." (a senior surgeon [1]).

\section{Discussion}

Analyzing interviews using CTA allowed understanding the thinking processes of healthcare staff while making clinical decisions about PAD. The palliative care approach for PAD is becoming more acceptable among health care professionals, with reports of its benefits for this population, yet it is often not implemented [17-18]. The end-stage of dementia is characterized by a high mortality rate, with a high likelihood of infections, eating problems, and other distressing symptoms. Many patients with advanced dementia undergo burdensome and aggressive interventions such as feeding tube insertion or repeated hospitalizations, inconsistent with a palliative approach [1]. Patients with advanced dementia are less likely to receive palliative care for their terminal situation [1, 19-20] than those with other terminal diseases [21-22]. The medical staff in acute settings tends to adopt a traditional care approach based on aggressive, life-prolonging therapy, although studies have shown that this approach does not lead to an improved prognosis or an improvement in the quality of life in this population [18, 23-24].

While the spectrum of treatment options for patients with advanced dementia with an acute medical problem ranges from "saving life at all costs" to "preventing suffering and symptomatic treatment," the majority of respondents focused on one extreme or the other, without expressing a range of treatment options. These polarized perspectives were expressed in the task descriptions and the end-of-life decisions and were highly associated with the medical specialty. Medical specialty may be strongly socialized, potentially inhibiting deviations from the unit norm. Avoidance of an alternative approach may be inculcated using paternalism, hierarchy, and authority [25]. Justification for the selected approach of care is argued on deontological or utilitarian grounds, such as relief from suffering by highly invasive procedures by surgeons as opposed to palliative care in medical wards. The cognitive process of decision-making for patients with advanced dementia may involve conflicting moral judgments [26].

Professional orientation is acquired during specialization training for the physicians and nurses at the initial stages of employment on a specific type of ward. Professional orientation is developed 
by socialization, internalizing the work climate, and adhering to the accepted standard of care of senior members of the staff advocate. These processes shape the perspectives through which a medical team member perceives the patient and the available standards of care [27-28]. Our results corroborate with the findings of another study that showed that the likelihood of implementation of palliative care in the last year of life among surgical patients was lower than among non-surgical patients [29]. Other studies have reported that some surgeons felt that not operating resulted in professional frustration. Surgeons preferred to act immediately to solve a medical condition, often without considering the long-term consequences [30-32]. Surgeons focused on individual organs of the patient rather than holistically, often considered as "dehumanization" and "depersonalization" [5, 33-34], an approach sometimes referred to as the "localization of the diagnosis" [35].

Our findings demonstrate the range of willingness of the healthcare staff to involve the family in the decision-making process from patient or family autonomy to paternalism. Medical staff influences the family members in ways they perceived as being in the best interest of the patient by helping them make a decision [35], while simultaneously trying to control the decision. Preference for patient/family autonomy over professional autonomy may result in decreased quality of care when the healthcare providers feel obligated to adhere to the family's values even when these values conflict with their own. An ethical question arises when the health care team is required to act in a way that is not medically justified, increasing patient suffering and resulting in "moral stress" [36]. To resolve this ethical dilemma, the World Medical Association published an international guideline [36] supporting physicians who refuse to act according to patient's requests when the treatment requested by the patient is regarded as inappropriate.

While a current trend is shared decision-making, the primary decision-makers in this study were often family members. Healthcare providers justified this approach anticipating their fear of the family's response to treatment decisions, concern for the family's interpretation of the healthcare provider's intentions, concern for legal ramifications, and providers' perceptions of the family's expectations of them. These findings are consistent with those of previous studies [21,37-42].

In this study, all of the physicians but only about half of the nurses described a hierarchy when making medical decisions. Traditionally, medical diagnosis and determination of prognosis have been a physician's responsibility. However, in practice, input from nurses plays a significant and proactive role in shaping patient communication [43]. A systematic review found that communicating with the nursing staff was a key part of the relationship between nurses and patients/families [44]. The role of the nursing staff in decision-making is characterized by advocacy of patient preferences and support for the family [45]. Nurses working with PAD were observed to provide information, empathy, emotional support, and assistance with decision-making for patients as well as family members [18]. Nurses have also been found to pressure the medical staff to accept family and patient preferences [45]. In contrast, nurses may be insecure in their role of promoting end-of-life discussions due to their perceived lack of communication skills and administrative support [46]. Previous studies have indicated a preference of nurses for palliative care and less aggressive therapies, while physician training stresses saving lives at any cost [45, 47-49]. Our study did not support this finding, possibly because the approach of nurses was consistent with that of physicians in each ward, suggesting professional identification with the local perceived norms. In addition, in this study, nurses were not independent decision-makers. Perhaps, in community or nursing home settings, where nurses are case managers, and they practice independently, the differences in approach between nurses and physicians would be more pronounced. 
A diagnosis of dementia should trigger recognition that the patient's condition is terminal. However, a discussion of death is perceived as a "taboo" [50]. Such was the case in this study. Avoiding such a discussion is a barrier to palliative care. If the family is not proactive in raising the issue of death, healthcare providers prefer to avoid it [51-54].

At first glimpse, there was great variability in the duration of the interviews. Some of the interviewees were eager to discuss a complex issue that frequently occurs in their clinical experience and were willing to expand the discussion. Other interviewees seemed uncomfortable discussing end-of-life care decisions; hence, they briefly answered questions without expanding the focus of the discussion. In addition, no association was found between the length of the discourse and the preferred treatment approach.

The interviews were based on hypothetical scenarios and were devoid of the complexity of everyday professional pressures. Participants expressed their favored therapeutic approach, which they reported as their individual preference toward appropriate care for a hypothetical patient. We assume that in real-life situations, treatment decisions considered several other factors such as collaboration with colleagues and family members, as well as accepted organizational norms and policies. Therefore, the final clinical decision might not be the personal preference of a healthcare provider. The interaction between personal preferences and actual practice was not included in the interviews for this study.

This study was conducted in two major hospitals in Israel. The sample was small, and the findings might not completely represent the population or other populations. The case presented was hypothetical, and we did not examine the thoughts or actions of the interviewees in a real case scenario. In addition, the case presented was surgically oriented, and it is possible that in a case with medical intervention such as mechanical ventilation, the findings would differ. The thought processes were evaluated from our subjective interpretation of the conversations and the words of the participants. Neither can we exclude the influence of social desirability on the participant's responses.

To the best of our knowledge, this is the first study examining the thinking processes of medical staff in the context of treatment decisions for PAD using the CTA method while simultaneously examining moral judgments and their impact on thought processes according to professional orientation.

The socialization of medical teams caring for those with advanced dementia as well as the process of shared decision-making with family members need further investigation. This study included medical staff members who had not received formal geriatric and/or palliative education and training. Notably, in many acute care wards, some of the staff might have received postqualifying specialty training and practice that may serve as a potential source of information and role modeling for the rest of the staff in the department. There may be significant differences in perceptions between senior and younger staff, as well as differences in cultures and religious orientation of staff members. Future research should address these issues. Given the limited study population, the validity of the findings in other settings should be examined while assessing the impact of organizational and administration policies on decision-making. Finally, it is also suggested to conduct a prospective study that assesses the decisions made in routine daily clinical work, including the interaction between personal preferences of care and decisions made. 


\section{Conclusions}

The findings of this study highlight the effect of thinking processes and non-clinical factors on medical practitioners' clinical end-of-life decision making. The most remarkable factor was the moral thinking paradigm associated with professional orientation based on affiliation to a specific type of medical unit. Two extreme treatment approaches were documented: the deontological approach that focused on the disease, and the utilitarian approach, which focused on a holistic perspective to treat patients. Another finding was an almost universal wish for shared decisionmaking with family members, often diverted by the hierarchical and authoritarian nature of the medical staff. Understanding the subjective, non-clinical aspects in medical decision-making may improve the quality of care that is of paramount importance regarding end-of-life and other treatment decisions in the case of advanced dementia patients.

\section{Acknowledgments}

The authors would like to thank the participants who shared their time and experiences to make this study possible.

\section{Author Contributions}

Meira Erel, Esther-Lee Marcus and Freda DeKeyser Ganz designed the study. Meira Erel performed data collection. Meira Erel performed data analysis, supervised by Esther-Lee Marcus and Freda DeKeyser Ganz. All authors contributed to writing of the manuscript.

\section{Competing Interests}

The authors have declared that no competing interests exist.

\section{References}

1. Mitchell SL, Teno JM, Kiely DK, Shaffer ML, Jones RN, Prigerson HG, et al. The clinical course of advanced dementia. N Engl J Med. 2009; 361: 1529-1538.

2. Van der Steen JT, Onwuteaka-Philipsen BD, Knol DL, Ribbe MW, Deliens L. Caregivers' understanding of dementia predicts patients' comfort at death: A prospective observational study. BMC Med. 2013; 11: 105.

3. Voumard R, Truchard-Rubli E, Benaroyo L, Borasio GD, Büla C, Jox RJ. Geriatric palliative care: A view of its concept, challenges and strategies. BMC Geriatr. 2018; 18: 220.

4. Mercadante S, Gregoretti C, Cortegiani A. Palliative care in intensive care units: Why, where, what, who, when, how. BMC Anesthesiol. 2018; 18: 106.

5. Thuné-Boyle IC, Sampson EL, Jones L, King M, Lee DR, Blanchard MR. Challenges to improving end of life care of people with advanced dementia in the UK. Dementia. 2010; 9: 259-284.

6. Timmons S, O'Shea E, O'Neill D, Gallagher P, de Siún A, McArdle D, et al. Acute hospital dementia care: Results from a national audit. BMC Geriatr. 2016; 16: 113.

7. De Vleminck A, Pardon K, Beernaert K, Deschepper R, Houttekier D, Van Audenhove C, et al. Barriers to advance care planning in cancer, heart failure and dementia patients: A focus group study on general practitioners' views and experiences. PloS One. 2014; 9: e84905. 
8. Hajjaj FM, Salek MS, Basra MK, Finlay AY. Non-clinical influences on clinical decision-making: A major challenge to evidence-based practice. J R Soc Med. 2010; 103: 178-187.

9. Greene JD, Nystrom LE, Engell AD, Darley JM, Cohen JD. The neural bases of cognitive conflict and control in moral judgment. Neuron. 2004; 44: 389-400.

10. Cushman F, Young L, Greene JD. Our multi-system moral psychology: Towards a consensus view. In: The moral psychology handbook. Oxford, UK: Oxford University Press; 2010. pp. 47-71.

11. Singer P. Ethics and intuitions. J Ethics. 2005; 9: 331-352.

12. Gholami K, Tirri K. The cultural dependence of the ethical sensitivity scale questionnaire: The case of Iranian Kurdish teachers. Educ Res Int. 2012; 2012: 387027.

13. Greene JD. Beyond point-and-shoot morality: Why cognitive (neuro) science matters for ethics. Ethics. 2014; 124: 695-726.

14. Bevan MT. A method of phenomenological interviewing. Qual Health Res. 2014; 24: 136-144.

15. Clark RE, Feldon DF, van Merriënboer JJ, Yates KA Early S. Cognitive task analysis. In: Handbook of research on educational communications and technology. 3rd ed. Mahwah, NJ: Lawrence Erlbaum Associates; 2008. pp. 577-593.

16. Tannen D. Discourse analysis-what speakers do in conversation [Internet]. New York: Linguistic Society of America; $2019 . \quad$ Available from: https://www.linguisticsociety.org/resource/discourse-analysis-what-speakers-do-conversation.

17. van der Steen JT. Dying with dementia: What we know after more than a decade of research. J Alzheimers Dis. 2010; 22: 37-55.

18. Mitchell SL, Kiely DK, Hamel MB. Dying with advanced dementia in the nursing home. Arch Intern Med. 2004; 164: 321-326.

19. Ryan T, Ingleton C. Most hospices and palliative care programmes in the USA serve people with dementia; lack of awareness, need for respite care and reimbursement policies are the main barriers to providing this care. Evid Based Nurs. 2011; 14: 40-41.

20. Ampe S, Sevenants A, Smets T, Declercq A, Van Audenhove C. Advance care planning for nursing home residents with dementia: Policy vs. practice. J Adv Nurs. 2016; 72: 569-581.

21. Erel M, Marcus EL, Dekeyser-Ganz F. Barriers to palliative care for advanced dementia: A scoping review. Ann Palliat Med. 2017; 6: 365-379.

22. Sachs GA, Shega JW, Cox-Hayley D. Barriers to excellent end-of-life care for patients with dementia. J Gen Intern Med. 2004; 19: 1057-1063.

23. Brazil K, Carter G, Galway K, Watson M, van der Steen JT. General practitioners perceptions on advance care planning for patients living with dementia. BMC Palliat Care. 2015; 14: 14.

24. Di Giulio PD, Toscani F, Villani D, Brunelli C, Gentile S, Spadin P. Dying with advanced dementia in long-term care geriatric institutions: A retrospective study. J Palliat Med. 2008; 11: 1023-1028.

25. Salvatore $D$, Numerato $D$, Fattore $G$. Physicians' professional autonomy and their organizational identification with their hospital. BMC Health Serv Res. 2018; 18: 775.

26. Herman M. Moral heuristics and biases. J Cogn Neuroethics. 2014; 73: 127-142.

27. Sirovich BE, Lipner RS, Johnston M, Holmboe ES. The association between residency training and internists' ability to practice conservatively. JAMA Intern Med. 2014; 174: 1640-1648.

28. Smith CD, Korenstein D. Harnessing the power of peer pressure to reduce health care waste and improve clinical outcomes. Mayo Clin Proc. 2015; 90: 311-312.

29. Olmsted CL, Johnson AM, Kaboli P, Cullen J, Vaughan-Sarrazin MS. Use of palliative care and hospice among surgical and medical specialties in the veterans' health administration. JAMA 
Surg. 2014; 149: 1169-1175.

30. Dillon BR, Healy MA, Lee CW, Reichstein AC, Silveira MJ, Morris AM, et al. Surgeon perspectives regarding death and dying. J Palliat Med. 2019; 22: 132-137.

31. Nabozny MJ, Kruser JM, Steffens NM, Brasel KJ, Campbell TC, Gaines ME, et al. Constructing high-stakes surgical decisions: It's better to die trying. Ann Surg. 2016; 263: 64-70.

32. Suwanabol PA, Reichstein AC, Suzer-Gurtekin ZT, Forman J, Silveira MJ, Mody L, et al. Surgeons' perceived barriers to palliative and end-of-life care: A mixed methods study of a surgical society. J Palliat Med. 2018; 21: 780-788.

33. Heschel AJ. The patients as a person. In: The insecurity of freedom: Essays on human existence. New York: Farrar, Straus and Giroux; 1966. pp. 24-38.

34. Tinetti ME, Esterson J, Ferris R, Posner P, Blaum CS. Patient priority-directed decision making and care for older adults with multiple chronic conditions. Clin Geriatr Med. 2016; 32: 261-275.

35. Heyd D. The medicalization of health: Plato's warning. Rev Int Philos. 1995; 49: 375-393.

36. Cave E. Selecting treatment options and choosing between them: Delineating patient and professional autonomy in shared decision-making. Health Care Anal. 2020; 28: 4-24.

37. Dening KH, Greenish W, Jones L, Mandal U, Sampson EL. Barriers to providing end-of-life care for people with dementia: A whole-system qualitative study. BMJ Support Palliat Care. 2012; 2: 103-107.

38. Ryan T, Gardiner C, Bellamy G, Gott M, Ingleton C. Barriers and facilitators to the receipt of palliative care for people with dementia: The views of medical and nursing staff. Palliat Med. 2012; 26: 879-886.

39. Stewart F, Goddard C, Schiff R, Hall S. Advanced care planning in care homes for older people: A qualitative study of the views of care staff and families. Age Ageing. 2011; 40: 330-335.

40. Bamford C, Lee R, McLellan E, Poole M, Harrison-Dening K, Hughes J, et al. What enables good end of life care for people with dementia? A multi-method qualitative study with key stakeholders. BMC Geriatr. 2018; 18: 302.

41. Maxwell CA, Mion LC. Geriatric trauma: An opportunity for proactive palliative care. Geriatr Nurs. 2015; 6: 475-476.

42. Paque K, Vander Stichele R, Elseviers M, Pardon K, Dilles T, Deliens L, et al. Barriers and enablers to deprescribing in people with a life-limiting disease: A systematic review. Palliat Med. 2019; 33: 37-48.

43. Dewar A. Nurses' experiences in giving bad news to patients with spinal cord injuries. J Neurosci Nurs. 2000; 32: 324-330.

44. Lowey SE. Communication between the nurse and family caregiver in end-of-life care: A review of the literature. J Hosp Palliat Nurs. 2008; 10: 35-45.

45. Adams JA, Bailey DE, Anderson RA, Docherty SL. Nursing roles and strategies in end-of-life decision making in acute care: A systematic review of the literature. Nurs Res Pract. 2011; 2011: 527834.

46. Sprinks J. Nurses lack confidence in providing end of life care. Nurs Older People. 2011; 23: 6-7.

47. Thacker KS. Nurses' advocacy behaviors in end-of-life nursing care. Nurs Ethics. 2008; 15: 174185.

48. Borowske D. Straddling the fence: ICU nurses advocating for hospice care. Crit Care Nurs Clin North Am. 2012; 24: 105-116.

49. Cheon J, Coyle N, Wiegand DL, Welsh S. Ethical issues experienced by hospice and palliative 
nurses. J Hosp Palliat Nurs. 2015; 17: 7-13.

50. Thulesius HO, Scott $\mathrm{H}$, Helgesson G, Lynöe N. De-tabooing dying control - a grounded theory study. BMC Palliat Care. 2013; 12: 13.

51. Collins J. Living and dying with dementia in Scotland: Barriers to care [Internet]. London: Marie Curie $\quad 2015.2$ Available from: https://www.mariecurie.org.uk/globalassets/media/documents/policy/policypublications/february-2015/living-and-dying-with-dementia-in-scotland-report-2015.pdf.

52. Hill EM. Investigating barriers to access and delivery of palliative care for persons with dementia in London, Ontario. London: Western University; 2014. Available from: http://ir.lib.uwo.ca/cgi/viewcontent.cgi?article=3784\&context=etd.

53. Hinkka $H$, Kosunen E, Lammi UK, Metsänoja R, Puustelli $A$, Kellokumpu-Lehtinen P. Decision making in terminal care: A survey of Finnish doctors' treatment decisions in end-of-life scenarios involving a terminal cancer and a terminal dementia patient. Palliat Med. 2002; 16: 195-204.

54. McKenzie EL, Brown PM, Mak AS, Chamberlain P. 'Old and ill': Death anxiety and coping strategies influencing health professionals' well-being and dementia care. Aging Ment Health. 2017; 21: 634-641.

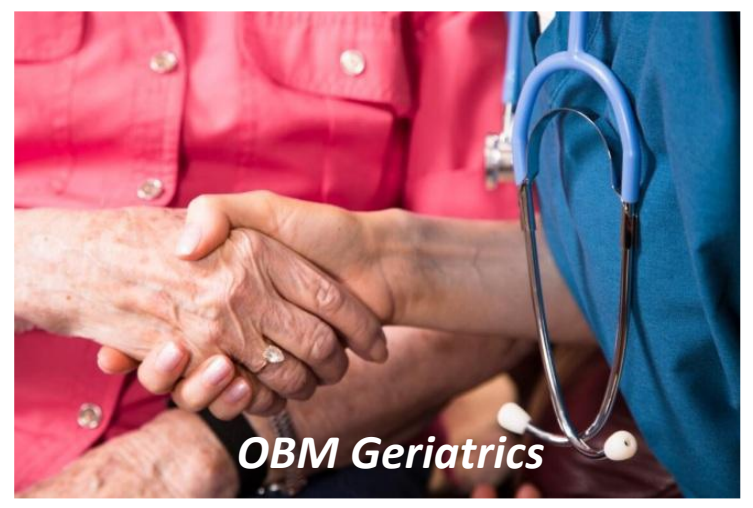

Enjoy $O B M$ Geriatrics by:

1. Submitting a manuscript

2. Joining in volunteer reviewer bank

3. Joining Editorial Board

4. Guest editing a special issue

For more details, please visit: http://www.lidsen.com/journals/geriatrics 